\title{
The Relevance of Classroom Audits and Student Feedback on Teacher Effectiveness
}

\author{
Robert P. Machera \\ Faculty of Accounting, Botho University, Botswana
}

Copyright $(2017$ by authors, all rights reserved. Authors agree that this article remains permanently open access under the terms of the Creative Commons Attribution License 4.0 International License

\begin{abstract}
Measuring of performance for lecturers' has become a popular event not only in the Botswana academic environment but in many parts of the world (16). Being charged with responsibilities as an AAT Team Leader the researcher was interested in getting feedbacks for faculty members in his department. This study focused on the relationship between classroom audits, student feedbacks and students' throughput. This study used a mixed method for data collection. This research positions itself into two paradigms between the adherents' quantitative approach 'QUAN' and qualitative approach 'QUAL'. The population for lecturers who were teaching AAT at Botho University during the time of the research was 23. A quantitative content analysis was followed with a focus group. The researcher used a convenient sampling to select 12 lecturers to participate in the focus group. Face-to- face interviews were conducted on 6 lecturers who were conveniently selected from the 12 participants who were part of the focus group. There were comparisons between quantitative content analysis, focus group and face- to- face interviews in order to determine the truth from the participants. The results of this study revealed that there was no relationship between the classroom audits, student feedback and students throughput. Additional instruments methods were recommended to evaluate lecturers' performance. The findings from this research may assist Botho University and other universities world-wide.
\end{abstract}

Keywords Classroom Audits, Student Feedbacks, Students' Throughput, Direct Observation, Indirect Observation and Effectiveness

\section{Introduction}

(11) state that teacher evaluation is widely used to develop and improve the standards of teaching in any educational set-up. Therefore, monitoring and evaluation of teachers or lecturers is perceived in education as continuous quality improvement that enhances the effectiveness of teaching at a school or university. Botho University in Botswana is one of the tertiary universities that consider monitoring and evaluation as part of continuous improvement. Students' feedback, classroom observations (audits) and pass rates are used as part of the index that measures the teacher's performance and effectiveness.

At Botho University, classroom audits and student feedbacks are used to measure performance of each faculty member. What is classroom audit? According to (14) and (4) a classroom audit is a process whereby a supervisor observes the lecturer in the classroom in order to obtain evidence on effective teaching. At Botho University a standard classroom audit is used during observation period. Apart from classroom audits an online student feedback is also used to measure the faculty's performance. This electronic student feedback is in a form of a questionnaire which is divided into the following three headings: Institution, Student and Lecturer.

Classroom audits are relevant to lecturers as they reflect positive and negative feedback in terms of performance. Positive performance may be used in the human resources department for promotional prospects and as well as for awarding salary increments. Negative feedback may be used for continuous improvements and training and development to the concerned individuals. The researcher was motivated to conduct this study in order to see whether it was appropriate for Botho University to finally conclude on how teachers perform using these two modes of feedbacks. The two modes of feedbacks appear to be very biased as they are embedded with the halo and horn effect. The halo and the horn effect form the basis for the conceptual framework with of this study. This research includes the concepts of the halo and the horn effect that brings in the phenomenon of biasness which is inherent in human beings. The halo effect was referred by (15) a psychologist as a cognitive (positive) bias whereby an observer's overall impression of a person influences the feelings and thoughts about the person's character or properties. The halo effect is perceived as the attractiveness in the person being observed, for example the observer is attracted by the person and tends to like or favour that particular individual. This philosophy may be applied to 
the students' where they are attracted with the teacher and then their judgement is positive which result in them rating high scores. The horn effect is the opposite for halo effect; it is whereby the observer tends to dislike the person being observed and then negatively award or rate that individual. The rating scores that the observed person is awarded would be influenced by the unattractiveness (clique) between the two individuals. This may be the same with either the student or the observer; therefore the negative judgement is then perceived as being biased. Therefore in most cases the evaluation of the lecturers / teachers using students' feedback and classroom observations may be either objective or subjective hence these two instruments may result into problems in monitoring and measuring teachers' performance and effectiveness.

\section{Statement of the Problem}

The above tools that are used for measuring lecturers' performance are they effective and efficient? Classroom audits and student feedbacks are associated with the phenomenon of halo and the horn effect which was discovered by a psychologist (15). (5) revealed that the halo effect was also present in the evaluation of school children by their teachers. The problem was how accurately and appropriately these instruments were? It is from this background that the researcher was motivated to investigate the relationship between classroom audits and students' feedback in line with throughput rates at Botho University. There have been some inconsistencies as a result of the tools that are used to measure teachers' effectiveness in the AAT department. It is imperative to find solutions that help to remove or minimise these discrepancies in order to enhance or promote these evaluation tools. In most cases it appears that it is not fair to give a final judgment on the teachers' performances or effectiveness based on the scores from these instruments. These discrepancies motivated the researcher to conduct this research in order to investigate relationships between the results of each instrument in line with students' throughput.

\section{Aim of the Study}

The main aim of this study was to investigate the relationships between the classroom audits and student feedback in line with students throughput as a mechanism for measuring teachers' performance and effectiveness, in to order establish the adequacy of these evaluation tools.

\section{Objectives of the Study}

The objectives of this study are as follows:

- To ascertain the relationship between classroom audits, student feedback and students pass rates.
- To ascertain the relationships between the students, observer and the individuals being observed.

- To make recommendations on possible additional tools for measuring lecturers performance and effectiveness.

\section{Research Questions}

The following are the research questions for this study:

- What are the relationships between classroom audits, student feedback and student's performance?

- What are the relationships between the students, observer and the individuals being observed?

- What are other additional instruments that may be used to measure lecturers performance?

\section{Contribution to the Knowledge Domain}

The significance of this study is that, it would benefit different stakeholders including lecturers, students, universities and colleges. The universities and colleges would then be able to use appropriate tools or instruments to measure academic staff. If this study is published it would add to the body of knowledge as different techniques for measuring academic staff are discussed in this research.

\section{Literature Review}

The research was also guided by different types of observation which includes: direct and indirect observation. Direct observation refers to a procedure whereby lecturers are observed by their supervisors during the contact sessions in their classrooms (3). Indirect observation is whereby lecturers are observed by any other means such as cameras without their knowledge. This study focuses on direct observation because indirect observation is associated with many ethical problems (3).

In addressing the problem of measuring performance, some theories and models have been selected to illuminate the possible answers to research questions posed above. According to (3) student feedbacks are constructive as they enhance educator's effectiveness. Administrators should not use student feedbacks and classroom audits as the sole performance measure (6). Student feedback is a management monitoring mechanism of what is happening in the classroom (2). Student feedback enhances the quality of teaching and improves the teacher student relationships (4). According to (11) teacher evaluation metrics such as student feedback and classroom observations should be used as teachers' performance indicators. The evaluation of teachers depend on the expertise of experienced university leadership, taking into cognisance all factors that impact on achievement and strengths of each appraisal instruments. 
(11) state that there are three common ways that are used to evaluate teacher effectiveness as follows: gains in tests scores, classroom observations and pupil surveys. The ways for measuring teacher effectiveness in (11) study are similar to those that are in this study. The following is a detailed explanation for the three ways that are used for monitoring and evaluating teachers' effectiveness, according to (11):

\section{Gains in test scores:}

Gains in the pupil tests scores were perceived is the best method / metric to be used in measuring performance for teachers. This metric is perceived to be objective though there are some shortcomings; it is the most reliable of the three measures of teachers' effectiveness. Tests and examinations are consistently used to judge the good and bad performing teachers.

\section{Classroom observations}

It is argued that even if the classroom observations are conducted by well- experienced and trained independent evaluators, the results may always be subjective and this method is regarded as the least metric of assessing teachers' effectiveness. If classroom observations are conducted in an objective manner they may lead to; constructive feedback, promote honesty between the evaluator and the teacher being evaluated hence this may act as a developmental instrument. The argument for using classroom observation may result into teachers pretending to be good performers due to the fact that they thoroughly prepare for the class before the observation day. This shows that the teachers will manipulate their behaviour during the observation period.

\section{Pupil surveys (students'feedback)}

Pupil surveys are open to abuse of power with many lecturers as they instil fear to the students and then feedback may be done under duress. However, in some instances the students lack fairness and as a result provide negative judgements especially to teachers who are very strict to them. Pupil surveys as a metric for teachers' performance is rated to be in middle ground between gains in tests scores and classroom observations. According to (11) study it appears that there is no measurement that is perfect as all measurements are vulnerable to manipulations and distortions. This was earlier explained in the halo and horn effects where the judgement for an individual is subject to biasness. (11) further state that schools and universities are using many other tools apart from these three discussed above in order to promote best practices and transparency.

\section{Research Methodology}

The research design that was followed in this study was a case study for lecturers at Botho University teaching Association of Accounting Technician programme. This study used a mixed method for data collection. This research positions into two paradigms between the adherents quantitative approach 'QUAN' and qualitative approach 'QUAL'. The quantitative approach collects data in the form of numbers and qualitative collects data in the form words and pictures hence the goal of qualitative is to deduce the participants' perceptions of reality and to draw conclusions about the truth, knowledge and authority (7). (12) postulate that focus group interviews were supported by other methods of data collection in order to enhance the validity and reliability of the study. Therefore content analysis, focus group and face -to- face interviews were used in order to triangulate the methods of collecting data (see figure 1). Triangulation of methods was also concurred by (10) as it enhances the validity of the study.

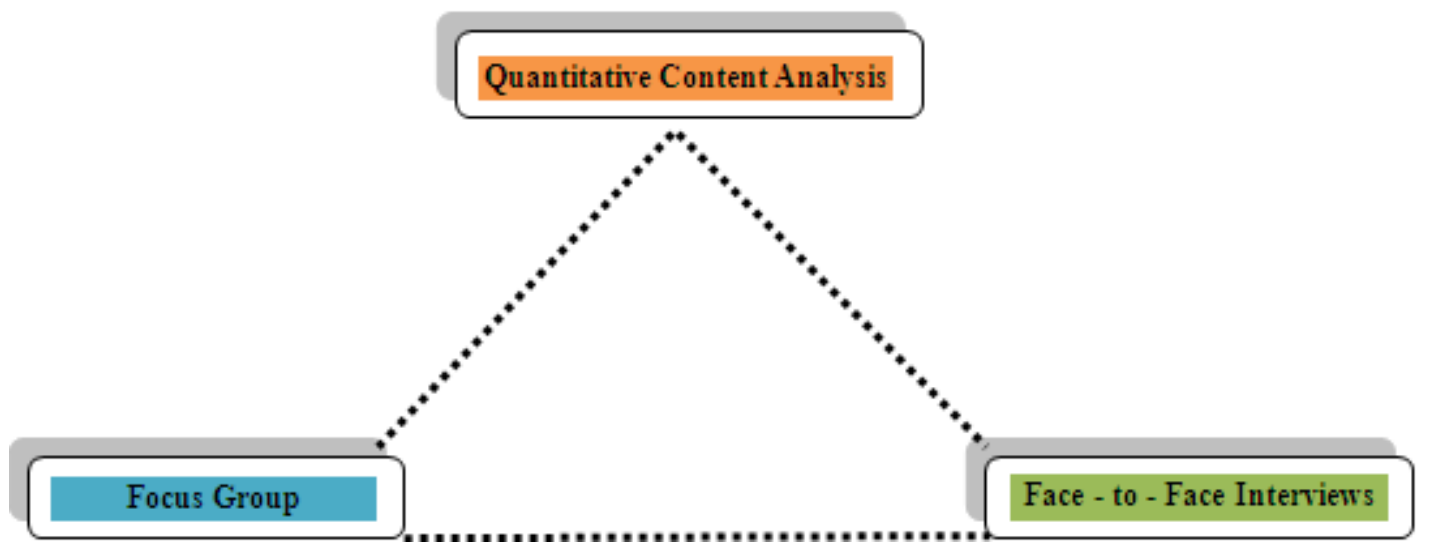

Figure 1. Triangulation of the methods (Adapted from the researcher) 


\section{Population and Sampling}

The research used students' feedback, teachers' classroom observations and students' pass rates as the variables for measuring the teachers 'effectiveness at Botho University in the department of Association of Accounting Technicians (AAT). The population for lecturers who were teaching AAT programme at Botho University during the time of the research was 23 . The researcher used a convenient sampling to select 12 lecturers to participate in the focus group. Face-to- face interviews were conducted on 6 lecturers who were conveniently selected from the 12 participants who participated in the focus group. There were comparisons between quantitative content analysis, focus group and faceto- face interviews in order to determine the truth from the participants. Interview schedules were used during the focus group and face - to face interviews. The findings from this research would assist Botho University and other universities world-wide.

\section{Ethical Considerations}

In his capacity as a researcher it was not good practice to plagiarise, or fabricate or falsify evidence or knowingly misrepresenting information or its source $(1 \& 13)$. The researcher managed to get the lecturers' consent to participate. (8) argues that protecting individual autonomy has long been a central principle in educational research; therefore the researcher did not coerce any lecturer to participate in this study. Furthermore the researcher did not divulge any information to third parties as this would be an infringement of the participants' rights to privacy. Finally original or actual names and batch numbers were not used in this study.

\section{Results / findings of the study}

\subsection{Content Analysis}

The following table 1.1 below shows the results of student feedback, classroom audits and student final results for AAT Accounts Preparation module. The researcher interpreted the outcomes of the three variables to find out whether there was a relationship between these three.

Table 1. Student Feedback, Classroom audits and pass rates

\begin{tabular}{|c|c|c|c|c|c|c|c|c|c|c|c|c|}
\hline & & $\mathrm{AAT}$ & nester & Accou & reparc & Modu & $\operatorname{an}-\mathrm{J}$ & 2014) & & & & \\
\hline Faculty & A & B & $\mathrm{C}$ & $\mathrm{D}$ & $\mathrm{E}$ & $\mathrm{F}$ & G & $\mathrm{H}$ & I & $\mathrm{J}$ & $\mathrm{K}$ & L \\
\hline Batch No. & 9 & 6 & 7 & 12 & 4 & 5 & 10 & 11 & 3 & 2 & 8 & 1 \\
\hline \multicolumn{13}{|l|}{ Feedback } \\
\hline \multicolumn{13}{|l|}{ Questions } \\
\hline Qn.10 & 2.8 & 3.2 & 3 & 3.6 & 3.6 & 1.4 & 3.3 & 2.0 & 3.8 & 4.0 & 3.2 & 3.1 \\
\hline Qn.11 & 3.4 & 3.1 & 3 & 3.4 & 3.1 & 2.1 & 3.1 & 2.6 & 3.7 & 3.3 & 3.0 & 2.7 \\
\hline Qn.13 & 3 & 2.4 & 1.4 & 3.3 & 1.7 & 1.8 & 2.9 & 1.4 & 3.8 & 2.7 & 2.7 & 1.3 \\
\hline Qn.14 & 2.7 & 2.6 & 2.3 & 3.6 & 3.3 & 1.4 & 2.7 & 1.9 & 3.8 & 4.0 & 2.7 & 2.6 \\
\hline Qn.15 & 2.8 & 2.8 & 2.1 & 3.0 & 3.5 & 1.6 & 3.0 & 3.1 & 3.8 & 4.0 & 3.2 & 2.7 \\
\hline Qn.16 & 3.3 & 2.9 & 1.9 & 3.4 & 3.6 & 1.4 & 3.1 & 2.3 & 3.6 & 4.0 & 2.9 & 2.6 \\
\hline Feedback & 3.0 & 2.8 & 2.3 & 3.4 & 3.1 & 1.6 & 3.0 & 2.2 & 3.8 & 3.7 & 3.0 & 2.5 \\
\hline & & & & & & & & & & & & \\
\hline Audits & 3 & 3 & 3.5 & 3.5 & 3 & 3.2 & 3.77 & 2.44 & 2.9 & 3 & 3 & 3 \\
\hline
\end{tabular}




\subsection{Analysis of the results/ Findings of the Study}

\subsubsection{Content Analysis}

The researcher made some comparisons between students' feedback, classroom observations and pass rates. The data used was extracted from the AAT department. The results were analysed and reflected that 4 faculty members $(\mathrm{C}, \mathrm{F}, \mathrm{H}$ and $\mathrm{L}$ ) who were shaded in red in table 1.1 did not achieved a minimum required score of $2.8 \%$ on student feedback. The worse scenario on the student feedback is $\mathrm{F}$ who scored an average of $1.6 \%$. On classroom audits $\mathrm{H}$ scored a $2.44 \%$ which was very low and all the other faculty members scored $3 \%$ and above. The pass rates were not favourable only 3 faculty members (F, H and I) managed to achieve $65 \%$ and above. The results reflected that 8 faculty members (A, B, C, D, E, G, J, K and L) scored below 50\%. The results for the module were not pleasant and it was important to compare student feedback and classroom audits.

The findings indicated that the student feedback, classroom audits and pass rates for only 1 faculty member (I) were congruently positive. The pass rate for $(\mathrm{H})$ was pleasant but the student rating and classroom audits were negative. This shows that there is an element of biasness embedded in the ratings. It is difficult to justify a pass rate of $71 \%$ when the faculty member was rated negatively. Faculty (F) was negatively rated by students but achieved a $65 \%$ pass rate. Faculty (D) was positively rated but achieved a negative pass rate; this reflects biasness in relation to human judgements. The results above have shown that there is no relationship between classroom audits, student feedback and pass rate. It was important for me to support this by conducting a focus group and face -toface interviews.

\subsection{Focus Group and Face-to- face Interviews}

11.3.1. Focus group interviews

\section{Question}

What is your perception towards classroom audits, student feedback and pass rates?

\section{Responses}

1) The majority of the faculty members agreed that there is no relationship between classroom audits, student feedback and pass rates. However the focus group argued that the problem is on the issues of biasness embedded in the evaluation tools.

2) Faculty members responded that their students are of low intelligent quotient (IQ) hence perform badly and it was obvious for the students to give them low scores as they were not happy with their results.

3) The group agreed that the classroom audits were conducted by staff members who lack educational background hence training for evaluators was important.
4) The majority of the respondents agreed that training should be offered to students on the importance of student feedback because some students were not taking feedbacks seriously.

\subsubsection{Face - to- face Interviews}

\section{Interview Faculty member ' $I$ '}

Are you happy with the classroom audits, student feedback and pass rates?

"I am partially happy because my classroom audit is on the lower side it shows an element of biasness from my supervisor". "I scored $90 \%$ pass rate on the module which is exceptionally good and this is in line with student feedback of $3.8 \%$ out of $4 \%$." "The problem is on the supervisor's rate which is far much lower as far as I am concerned."

\section{Interview Faculty member ' $D$ '}

What is your comment on the student feedback and classroom audits in relation to your student pass rates?

"The student feedback and classroom audits were very positive but the pass rate was very low. The low pass rate was caused by lack of student preparedness and as well as a tight milestone". I have good interpersonal skills and this assisted me to be rated highly with my students".

\section{Interview Faculty member ' $H$ '}

Can you justify your higher pass rate of $71 \%$ against lower scores for student feedback and classroom audits?

"The batch managed to get a higher pass rate through my efforts and the feedback and classroom audits were subjective since they are negative"

\section{Interview Faculty member ' $F$ '}

Are you able to justify your $1.6 \%$ lower score on student feedback?

"The lower score of $1.6 \%$ is very biased as it is proved by a good pass rate of $65 \%$ followed by a $3.2 \%$ positive rating from the classroom audits".

\section{Interview Faculty member ' $C$ '}

Your student feedback, classroom audits and pass rate were too extreme? How do your justify these extreme which were low student feedback, high classroom audits and lower pass rate?

"The students in batch 7 they hate me, I tried to motivate them but it proves that it's a folk of dull students." The students' feedback was biased and the $40 \%$ pass rate was contributed by lack of internal motivation in those dull students".

\section{Interview Faculty member ' $L$ '}

"The students in batch 1 biased, I tried to motivate them but it proves that it's a bunch of dull students." The students' feedback was biased and the $35 \%$ pass rate was contributed by lack of intrinsic motivation within the students". 


\section{Summary}

There was a triangulation of methods in order to rigorously get the truth from the findings. The focus groups and personal interviews highlighted the perceptions of faculty members in relation to the content analysis which was provided by the Faculty of Accounting and Finance. The results reflected that there was no relationship between classroom audits, student feedback and pass rates. Recommendations to improve the teacher evaluation were made in the following section.

\section{Recommendations}

The findings in this study proved that it was difficult to rate the teacher using student feedback, classroom audits and pass rate and hence made the following recommendations:

- Classroom audits should be conducted with independent evaluators who have educational background

- Arrange trainings and awareness for classroom audits

- Implement trainings and workshops for students on the importance of student feedback

- Include interpersonal skills and communication skills in the evaluation of faculty members

- Use a 360 degree performance appraisal to rate the faculty members

- Use Management By Objectives (MBO) to rate faculty members

- Encourage faculty members to enrol for Postgraduate Diploma in Higher Education (PGDHE) in order for them to improve their teaching approaches, assists non- performing lecturers and enhances the best performers

- Take corrective action after student feedback and classroom audits

- Introduce a balanced score card to measure performance of faculty members

- Conduct separate motivational trainings and workshops for students and faculty members (popular motivational public speakers)

- Conduct students and lecturers get together workshops (networking platforms)

\section{Conclusions}

It is imperative to measure the performance of academic staff using appropriate instruments or tools. Lastly it is very rare to obtain results that are the same from classroom audits, student feedback and students' results as these instruments are subjective in nature. Finally the researcher challenged educators to come up with instruments, in which all the three variables (student feedback, classroom audits and pass rates) are in agreement or align to each other. It is best practices to measure the performance of lecturers through the number of students who drop-out from the programme, number of students who complete the programme and also consider the number of graduates who are employed after completion of an academic programme in which the student is enrolled (9) and (16).

\section{REFERENCES}

[1] American Anthropological Association. (2012). Statement on Ethics: Principles of Professional Responsibilities.

[2] Buhagiar, M., A. (2013). Mathematics student teachers' view on tutor feedback during teaching practice. European Journal of Teacher Education 36 (1) 55 - 67.

[3] Cleary, M., Happell, B., Lau, S., T and Mackey, S. (2013). Student feedback on teaching: Some issues for consideration for nurse educators. International Journal of Nursing Practice 19 (1) $62-66$.

[4] Crooks, K., J. (1998). Classroom research: implementing the scholarship of teaching. In Class- room assessment and research: An update on uses, approaches, and research findings, ed. T. Angelo, 5 - 12. San Francisco, CA: Jossey Bass Publishers.

[5] Foster, Glen; James Ysseldyke (1976) "Expectancy and Halo effects as a result of artificially induced Teacher bias". Journal of Abnormal Child Psychology 21 (5): 519 - 533.

[6] Langbein, L. (2007). Management by results: Student evaluation of faculty teaching and the mis- management of performance. Economics of Education Review 27 (1) : 417 428 .

[7] Lather, P. (1992). Critical frames in education research: Feminist and post-structural perspectives. Women's studies international forum 31 (2):87-99.

[8] Lucas, K., B. and Lidstone, J, G. (2000). Ethical issues in teaching about research ethlics. Evaluation and Research in Education 14 (1): 51-72.

[9] Machera, R., P. 2016. Student Perceptions of Factors Influencing Throughput in an Accounting Programme: MPhil Thesis: South Africa: University of Stellenbosch.

[10] Mouton, J. (2001). How to succeed in your Master's \& Doctoral Studies: A South African Guide and Resource Book. Pretoria: Van Schaik.

[11] Murphy, R. and Lampl (2013). Testing Teachers: What works best for teacher evaluation and Appraisal: Improving social mobility through education: United Kingdom: The Sutton Trust.

[12] Northcutt, N. and McCoy, D. (2004). Interactive Qualitative Analysis: A Systems Method for Qualitative Research. London: Sage.

[13] Professional Responsibilities. Arlington, VA: American Anthropological Association. Available at: http:// www.aaanet.org/ethics/ upload / statement - on - Ethics Principles - of Professional - Responsibility.pdf 
[14] Robbins., P. Odendaal, A. and Roodt, G. (2003). Organizational Behaviour. Global and Southern African Perspectives. Cape Town: Pearson Education South Africa.

[15] Thorndike, E. (1920). Constant Error in Psychological
Ratings. Educational Psychology 1 (1): 13 - 27.

[16] Wingfield, B. (2011). Can we improve postgraduate degree throughput rates? Afr JSci. 2011:107 (11/12), Art. \#967, 2 pages. http://dx.doi.org/10.4102/sajs.v107i11/12. 